\title{
Teaching Tree-Thinking to Undergraduate Biology Students
}

\author{
Richard P. Meisel
}

Published online: 27 July 2010

(C) Springer Science+Business Media, LLC 2010

\begin{abstract}
Evolution is the unifying principle of all biology, and understanding how evolutionary relationships are represented is critical for a complete understanding of evolution. Phylogenetic trees are the most conventional tool for displaying evolutionary relationships, and "tree-thinking" has been coined as a term to describe the ability to conceptualize evolutionary relationships. Students often lack tree-thinking skills, and developing those skills should be a priority of biology curricula. Many common student misconceptions have been described, and a successful instructor needs a suite of tools for correcting those misconceptions. I review the literature on teaching tree-thinking to undergraduate students and suggest how this material can be presented within an inquiry-based framework.
\end{abstract}

Keywords Phylogenetics · Tree-thinking - Learning cycle · Nature of science - Great chain of being $\cdot$ Ladderized thinking

\section{Introduction}

Non-specialists and beginning biology students need to be taught to read modern evolutionary trees just as beginning students of geography need to be taught to read maps. (O’Hara 1997)

R. P. Meisel $(\bowtie)$

Cornell University,

227 Biotechnology Bldg,

Ithaca, NY, USA14853

e-mail: meisel@cornell.edu
Evolution is the unifying principle of all biology (Dobzhansky 1973). Most undergraduate biology students, however, fail to grasp core concepts in evolution (Jensen and Finley 1996; Baum et al. 2005; Meir et al. 2007; Gregory 2008; Gregory 2009). In fact, misconceptions about evolution are common amongst graduate students of biology (Gregory and Ellis 2009), and many professional biologists struggle to accurately interpret evolutionary relationships in their writings (Krell and Cranston 2004; Crisp and Cook 2005; Nee 2005). This suggests that evolutionary thinking does not come naturally to most people, and achieving an intuitive understanding of evolution is very difficult.

Phylogenetic trees display the evolutionary relationships of species or groups of species, and understanding phylogenies is critical for understanding evolution (Baum and Offner 2008). Evolutionary relationships are unique from other groupings based on similarities because evolutionary relationships are the result of descent from a common ancestor. An important consequence of the evolutionary process is that it produces nested hierarchical relationships between species and groups of species. If students are to correctly understand and interpret phylogenies (if they are to become "tree-thinkers"), they must develop an intuitive understanding of evolutionary relationships based on nested hierarchies (Baum et al. 2005; Catley et al. 2005; Baum and Offner 2008). Unfortunately, biology curricula often devote excess attention to microevolutionary concepts at the cost of time spent on macroevolution topics such as phylogenetics (Catley 2006). Here, I review the literature on teaching tree-thinking to undergraduate students, and I present some advice for introducing this material in an inquiry-based framework. The implementation of these approaches could help correct the dearth of focus on macroevolution. 


\section{Teaching Philosophy}

The tone of this review reflects the teaching philosophy of the author, and many of the recommendations are couched within a framework of inquiry-based learning (e.g., Goldsmith 2003; Giese 2005; Julius and Schoenfuss 2006). Additionally, teaching about evolutionary biology offers an excellent opportunity to introduce students to the scientific method and nature of science (NOS). The inquiry-based lessons are intended to familiarize students with the scientific method, which is thought to develop student understanding of NOS (Haukoos and Penick 1983). Understanding NOS is widely accepted to be a primary goal of science education (Lederman 1992). Lederman and colleagues consider a student to have a comprehensive understanding of NOS if they know that scientific knowledge is tentative, empirically based, partly the product of human creativity, and socially embedded (Abd-El-Khalick et al. 1998; Lederman 1998). Additionally, they consider it critical that a student know the difference between observations and inferences, as well as the distinction between scientific theories and laws. NOS should not be confused with the scientific process; it refers to the epistemological underpinnings of scientific inquiry (Lederman 1998).

To ensure that NOS concepts are absorbed by the students, I advocate presenting the material using the learning cycle (Lawson 1988). In this pedagogical approach, students confront their misconceptions through exploration and hypothesis testing. This fits within the conceptual change framework of science education in which students' preconceptions are considered and integrated into the instructional plan (Treagust and Duit 2008). Unlike traditional textbook presentations that merely introduce terminology and provide examples, the learning cycle encourages students to familiarize themselves with the questions at hand before learning the terminology; once they have some familiarity with the basics, they can explore concepts in more detail (Musheno and Lawson 1999). The learning cycle both encourages critical thinking and parallels the scientific method (Lawson 1988).

A substantial amount of research has been performed to test whether inquiry-based lessons improve primary and secondary level science teachers' understanding of NOS (reviewed in Abd-El-Khalick and Lederman 2000); I will treat science teachers as a proxy for undergraduate biology students because of this large body of literature. Abd-ElKhalick and Lederman (2000) conclude from these studies that for inquiry-based lessons to improve NOS understanding they must include explicit instruction on NOS along with a period of critical reflection. Merely assuming students will absorb NOS concepts by "doing science" will not lead to an understanding of NOS (Abd-El-Khalick and Lederman 2000). Therefore, if an instructor intends to teach
NOS along with tree-thinking using the exercises described below, the instructor should be sure to discuss what aspects of NOS students are implementing and exploring in each exercise.

\section{Common Misconceptions}

Students' preinstruction beliefs play an important role in learning new science material, and these preconceptions must be taken into account (Treagust and Duit 2008). Therefore, before we can address ways to teach treethinking, we must consider the common misconceptions students bring with them; students will confront these misconceptions using the learning cycle (Lawson 1988). Students often enter introductory courses with an understanding of evolution that parallels that of pre-Darwinian biologists (Rudolph and Stewart 1998; Sandvik 2008), which, simply stated, consists of a teleological interpretation of the evolutionary relationships of species (Gee 2002). This is commonly referred to as "The Great Chain of Being" (Lovejoy 1936; Nee 2005), in which evolution has progressed from "simpler" organisms to more "advanced" ones, culminating with the perfect creation: human beings (O'Hara 1997). The major flaw in this reasoning is that it assumes that currently living (extant) species are the "primitive" forms from which more "advanced" species descended. In a phylogenetic context, however, all extant species are descended from a most recent common ancestor (MRCA) to whom they are all equally related (Fig. 1a). The evolutionary lineages emerge via cladogenesis (the splitting of a single lineage into two distinct lineages) when a single population or species is split in two. The most common student misconceptions have been reviewed recently (Gregory 2008), and I will only give a brief introduction of the two main types of mistakes that students make.

Reading along the tips and ladderized misinterpretations One symptom of a teleological conception of evolutionary relationships is a ladderized interpretation of the evolutionary process in which "primitive" species give rise to "advanced" species. This can lead students to misread phylogenies by using the relative order of species along the tips to infer the relatedness of those species (Meir et al. 2007). For example, in Fig. 1a, a student may misinterpret species $\mathrm{B}$ and $\mathrm{C}$ as being more closely related than species $\mathrm{B}$ and $\mathrm{D}$; the correct interpretation is that $\mathrm{B}$ and $\mathrm{C}$ share the same MRCA as B and D. This is especially pronounced in more diagonal (or "ladder-like") representations, such as the tree on the right in Fig. 1a (Novick and Catley 2007; Baum and Offner 2008). When reading along the tips, students usually read from left to right (Meir et al. 2007), and, in doing so, they often perceive species on the left of 
a)
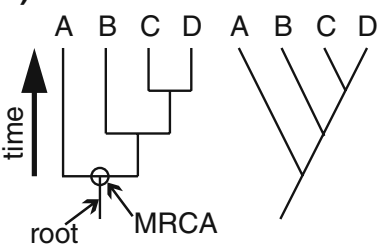

c)
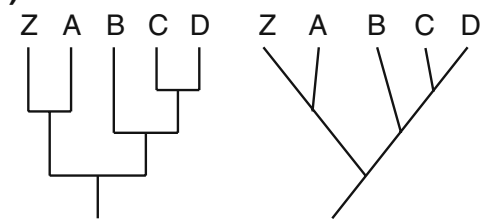

d)

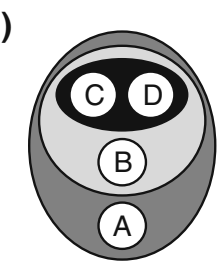

e)
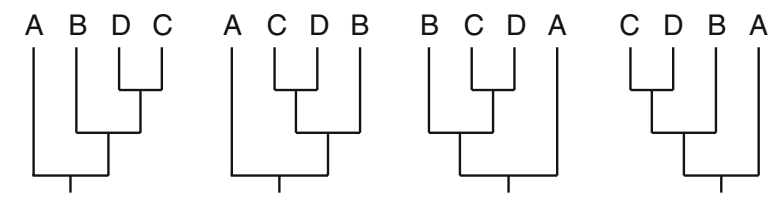

A B D C
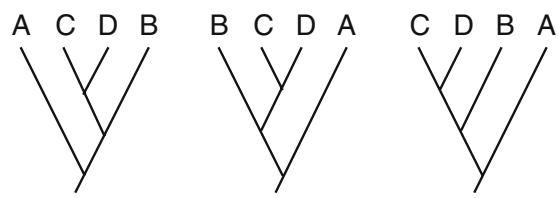

Fig. 1 Phylogenetic trees show the relationships of four species $(\mathrm{A}, \mathrm{B}, \mathrm{C}$, and D). Each tree represents the same relationships of the four species: species $\mathrm{C}$ and $\mathrm{D}$ are the closest relatives, species $\mathrm{B}$ is equally related to both $\mathrm{C}$ and $\mathrm{D}$, and species $\mathrm{A}$ is the outgroup. a $\mathrm{A}$ large arrow indicates the direction of time from the past to the present. The most recent common ancestor $(M R C A)$ of all four species is indicated by a circle and small arrow. An arrow indicates the root of the tree. The tree on the right is a diagonal representation of the evolutionary relationships. b Two clades are indicated on each tree: clade 1 consists of species $\mathrm{C}$ and $\mathrm{D}$, and it is nested within clade 2, consisting of species B, C, and D. c A fifth species $(Z)$ has been added to the phylogeny, but the relationships of species $\mathrm{A}, \mathrm{B}, \mathrm{C}$, and $\mathrm{D}$ have not changed. d A circles-within-circles diagram can represent the nested hierarchical relationships of species A, B, C, and D. e The branches of the tree have been rotated around various nodes, but they still depict the same evolutionary relationships

the tree as being ancestors of those on the right of the tree (Baum et al. 2005; Baum and Offner 2008). For example, a student may misinterpret Fig. 1a as suggesting that B evolved from A, C evolved from B, and D evolved from C. This suggests that students mistakenly view extant species as the ancestors of other extant species, but this is impossible in the correct interpretation of a phylogenetic tree (Baum and Offner 2008). It also suggests a misinterpretation that some extant species are "primitive" while others are "advanced" (Omland et al. 2008), but all extant species are equally diverged from their MRCA. The correct interpretation of the tree is that $\mathrm{A}, \mathrm{B}, \mathrm{C}$, and $\mathrm{D}$ share a MRCA at the root of the tree; $\mathrm{B}, \mathrm{C}$, and D share a MRCA more recently; and $\mathrm{C}$ and $\mathrm{D}$ share a MRCA most recently.
Clade density and node counting Phylogenetic trees can be divided into monophyletic clades, which are hierarchically nested units (Fig. 1b). A monophyletic clade contains an ancestral node (or branching point) and all lineages that descend from that node- for example, clade 1 (Fig. 1b) contains species C and D and their MRCA. Species B and $\mathrm{C}$ are a paraphyletic clade if species $\mathrm{D}$ is excluded (because species D shares a MRCA with $\mathrm{C}$ more recently than the MRCA of B and C). Students' incorrect perceptions of the "primitive/advanced" nature of extant species can be influenced by the species density of a clade. Species-poor clades are often incorrectly perceived as "primitive," while species-rich clades are incorrectly thought of as "advanced" (Krell and Cranston 2004; Crisp and Cook 2005; Omland et al. 2008). The species density of a clade, however, is often the result of incomplete sampling. This concept can be reinforced for students by showing a phylogeny with Homo sapiens (a species students perceive to be "advanced") in a species-poor clade (Omland et al. 2008). One possible explanation for the misinterpretation of clade density is that students may perceive a straight line as equivalent to no change occurring along that lineage (Meir et al. 2007). This may be especially pronounced in diagonal representations, where a Gestalt interpretation of straight lines leads to the conclusion that the line represents a single entity (Novick and Catley 2007). The long line leading to species A could be misinterpreted as meaning that species $\mathrm{A}$ has not changed at all since the MRCA. An instructor can reveal the fallacy of this interpretation by adding additional species to the tree. For example, when species $\mathrm{Z}$ is added to the tree, the long lineage leading to $\mathrm{A}$ is split in half (Fig. 1c). Additionally, adding characters to the tree (Fig. 2)

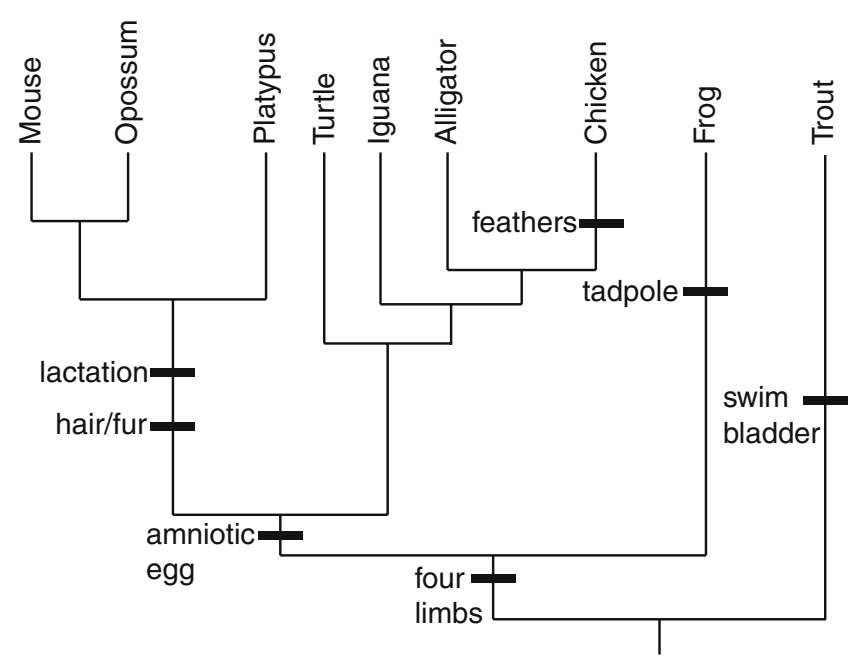

Fig. 2 Characters have been mapped onto a tree (the branches are not drawn to scale). Black bars show upon which branch a character evolved. Given this tree, students should be able to infer the characters in each of the extant species 
can also help improve student comprehension of diagonal trees (Novick et al. 2010).

Finally, students often misinterpret the number of nodes differentiating species as a meaningful measure of the evolutionary distance between the tips (Meir et al. 2007). The only proper measure of evolutionary distance between species is the time since the MRCA. The arrow of time is represented in Fig. 1a, showing that distance is measured vertically in the tree and not by the number of nodes differentiating species. The correct interpretation can be demonstrated by comparing Fig. 1a, with Fig. 1c. When only four species are considered, species $\mathrm{A}$ and $\mathrm{B}$ are separated by two nodes and species $\mathrm{B}$ and $\mathrm{D}$ are separated by two nodes (Fig. 1a). Species B and D share a MRCA more recently than $\mathrm{A}$ and $\mathrm{B}$, but the two species pairs are separated by the same number of nodes. Therefore, node counting is not a reliable estimate of evolutionary distance. Additionally, when species $\mathrm{Z}$ is added to the tree (Fig. 1c), species A and B are now separated by three nodes. A student who counts nodes to measure evolutionary distance will misinterpret this to mean that $\mathrm{A}$ and $\mathrm{B}$ are more distantly related to each other in Fig. 1c than in Fig. 1a when, in fact, they are equally related in both trees. Because evolutionary distances should not be changed by merely adding species to a tree, node counting is not an accurate way to measure evolutionary distance.

\section{Correcting Misconceptions}

Much of the evolution instruction students receive in schools centers around microevolutionary concepts, such as natural selection, and there is ample opportunity to introduce new macroevolutionary lessons to many curricula (Gilbert 2003; Catley 2006). To do so requires developing the tree-thinking skills of students. Following the example of Baum et al. (2005), I will focus only on how to teach students to interpret trees and not how phylogenetic trees are constructed. Some of these approaches will require students to develop their own ad hoc tree-building methods, but they need not receive instruction on any of the vast array of tree-building algorithms available (e.g., Page and Holmes 1998; Nei and Kumar 2000). Specific tree-building algorithms can be introduced to students only after they understand what a phylogenetic tree represents. The approaches to teaching tree-thinking presented here deal primarily with developing the students' conceptual understanding of phylogenies and less on terminology (Goldsmith 2003).

These suggestions and exercises are designed to have students confront their misconceptions and reconsider their preconceived misunderstandings of evolutionary relationships. To help students properly interpret their preconceptions, appropriate examples must be given. Students correctly interpret rectangular trees more intuitively than diagonal trees (Novick and Catley 2007; Baum and Offner 2008). Indeed it is not clear whether any more than a small fraction of untrained undergraduate students can correctly interpret a diagonal tree (Novick and Catley 2007; Sandvik 2008). Unfortunately, many, if not most, of the trees in textbooks are diagonal (Catley and Novick 2008), even though rectangular trees dominate the scientific literature (Novick and Catley 2007). The reason for the over-use of diagonal representations in textbooks is unknown, but one possibility is that diagonal trees allow us to tell evolutionary stories leading to a particular tip. To make matters worse, phylogenetic trees are often presented in textbooks without any explanation of how they should be interpreted, and these trees sometimes take unconventional forms (Catley and Novick 2008). These unconventional forms do not accurately represent evolution as a branching process, and students often have teleological and other incorrect interpretations of these unconventional representations (Catley et al. 2010).

Finally, introductory biology texts will use a phylogenetic tree of extant species to demonstrate the evolution of various characters in a clade of interest. This can be problematic when extant species are used to illustrate ancestral states (Omland et al. 2008). For example, if this is done for the evolution of plants, students could misinterpret evolution as a progression from extant nonvascular plants (e.g., mosses) to extant vascular seedless plants (e.g., ferns) to extant seed-bearing plants to flowering plants. While extant species can be useful for demonstrating ancestral states, instructors must ensure that they explicitly discuss how extant species are not ancestors of other extant species.

Basic concepts and simple tricks Before introducing specific exercises that can be carried out to train students in treethinking, I will present some basic concepts that should be emphasized throughout the lessons. First and foremost, trees should be taught as nested hierarchies. One way to demonstrate this is to use circle-within-circle diagrams (Fig. 1d) that visually represent the hierarchical nature of the relationships (Catley et al. 2005). These diagrams are ideal for introducing the concept of clades. Many of the problems students have in reading phylogenetic trees stem from reading them as ladders of progress from left to right (Meir et al. 2007; Gregory 2008). Simply using proper terminology may help discourage this misinterpretation, such as using "sister groups" to refer to species or clades on a tree that share a MRCA more recently with each other than with other species or clades (Krell and Cranston 2004; Gregory 2008; Omland et al. 2008). For example, species $C$ and $D$ are sister groups, and clade 1 is a sister group to species B (Fig. 1). This reinforces the concept that extant species cannot be "primitive" or "advanced." 
Merely explaining the nested hierarchical structure of trees and using proper terminology will probably not correct students' misconceptions. An instructor should also show that trees can be rotated around any node and still present the same information regarding the evolutionary relationships of the species (Fig. 1e). Various tricks have been suggested to aid in this demonstration (Crisp and Cook 2005; Omland et al. 2008). For students that prefer a tactile example, phylogenies can be constructed using pipe cleaners (Halverson 2010). Additionally, a phylogenetic tree can be thought of as a mobile (Baum and Offner 2008), and an instructor can provide an actual mobile for students to physically manipulate in class.

The left-to-right reading of trees may be inadvertently encouraged by the placement of species students may perceive as "advanced" on the rightmost tip (Omland et al. 2008). Interestingly, humans are usually placed furthest right in phylogenies found in textbooks (Sandvik 2009), which may encourage left-to-right, "primitive-to-advanced" thinking in students. A simple trick is to place humans elsewhere in the phylogeny by rotating around the nodes (Baum et al. 2005) or placing humans on a long branch attached to the root of the tree (species A in Fig. 1; Omland et al. 2008).

The relatedness of family members can also be used to demonstrate the flaw in ladderized thinking (Omland et al. 2008). In Fig. 1a, imagine $C$ and $D$ are brothers, $B$ is their first cousin, and $\mathrm{A}$ is their second cousin. A ladderized interpretation would say that A is oldest, B is next oldest, and $\mathrm{C}$ and $\mathrm{D}$ are either the same age or $\mathrm{C}$ is older than $\mathrm{D}$. The tree, however, says nothing about the ages of the four relatives. This can be further illustrated by diagramming the relationships of famous families (Omland et al. 2008). This analogy could backfire if not carefully implemented, and instructors who use this type of example should stress that the process giving rise to family members (i.e., mating between two individuals) differs from that which gives rise to evolutionary relationships (i.e., cladogenesis).

To show how pedigrees are related to phylogenies, a series of diagrams can be used (Baum and Offner 2008). Starting with a pedigree, an instructor can show how that pedigree fits within a genealogy of the entire population in which that family is found. The population genealogy can be shown to be part of a larger tree diagramming the relationships of all individuals in that species. Finally, one can zoom out further to show how the relatedness of individuals is extended to the evolutionary relationships of different species. This demonstration has the added bonus of linking tree-thinking and population thinking (O'Hara 1997) into a coherent framework.

Tree-thinking exercises Many of the current approaches for teaching phylogenetics bombard students with terminology, and they fail to absorb the key concepts (Goldsmith 2003).
This is antithetical to inquiry-based teaching approaches (such as those that implement the learning cycle) and pedagogical techniques designed to develop an understanding of NOS. Instead of focusing on terminology, the following exercises are designed to develop students' conceptual understanding of phylogenetics and NOS. As mentioned previously, if student understanding of NOS is a goal, an instructor should accompany these inquiry-based lessons with critical reflection of the NOS topics they address (Abd-El-Khalick and Lederman 2000).

Goldsmith (2003) proposed an introductory exercise, called "The Great Clade Race," that has been shown to improve tree-thinking in undergraduates (Perry et al. 2008). Groups of students are given eight index cards with shapes drawn on each card (Fig. 3). They are told that the cards are the result of a race through the woods with one starting line, multiple forks, and multiple finish lines. Each card was carried by a different runner, and each symbol on the card represents a stamp earned at a checkpoint along one of the straight-aways between the forks. The students are then asked to draw a map of the course given only the cards. This represents the exploration phase of the learning cycle. The exercise is followed by an introduction to the terms that describe various features of the racecourse/tree-each runner's course consists of branches, each split between courses is a node, and runners of similar courses form monophyletic clades united by synapomorphies (shared derived characters). There is only one correct branching order, but the students may represent their trees in different ways; this provides an opportunity to illustrate how different representation of the same data can contain identical information. After completing the exercise, the students can apply the concepts they have learned to actual biological examples. Additional clade race exercises have been proposed to introduce students to more advanced topics (Goldsmith 2003), but they will not be covered here.

The Great Clade Race requires an environment in which students can work in groups, and it may not be feasible to implement in large lecture courses. However, it may work in a course that uses peer instruction in addition to or rather than

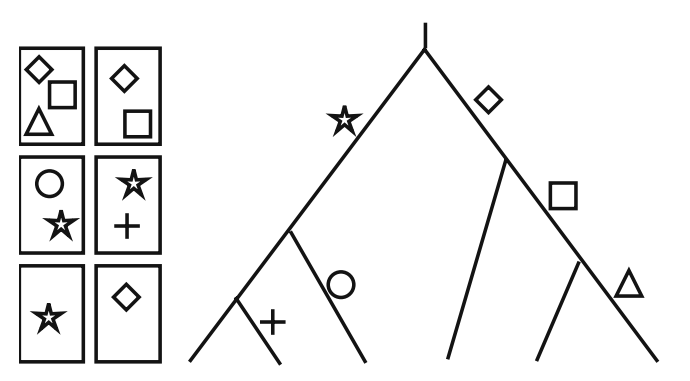

Fig. 3 An example of the Great Clade Race (Goldsmith 2003) is shown, with one possible solution. The rectangles represent index cards with symbols drawn on them 
lectures (e.g., Mazur 2009; Smith et al. 2009). If one cannot implement the Great Clade Race in a lecture course, computer simulations also increase student understanding of phylogenies (Perry et al. 2008). The simulation exercises can be carried out within a learning cycle in much the same way as the Great Clade Race. Interestingly, neither the Great Clade Race nor computer simulations significantly improve students' misconceptions about node counting (Perry et al. 2008), suggesting that subsequent exercises should emphasize why node counting is flawed. Additionally, students have difficulty inferring the characters of extant species given evolutionary transitions marked on a tree (Fig. 2) both before and after the exercises (Perry et al. 2008).

The fact that students have a difficult time understanding how characters can be mapped onto a tree (Fig. 2) after the Great Clade Race or computer simulations (Perry et al. 2008) suggests that other exercises are needed. One such exercise involves students observing organisms (either live organisms, bones, or other preserved remains) and testing hypotheses about the evolutionary relationships of the species (Singer et al. 2001). These exercises can be performed without having students build trees by presenting them with multiple trees (hypotheses) that they test given their observations (Giese 2005). Throughout the exercise, students map characters onto a tree, inferring both the properties of extant species and those of their extinct ancestors. Instead of morphological comparisons, DNA or protein sequences of different species can be analyzed. Molecular data such as these may be useful for correcting ladderized thinking because DNA and protein sequences are likely to evolve at similar rates along different evolutionary lineages; this may prevent students from inferring that one extant species is the ancestor of another extant species (Omland et al. 2008).

The learning cycle is easily applied to exercises that map characters onto trees (Giese 2005). Once students have developed a hypothesis about the evolutionary relationships of the species under consideration, the students defend their hypothesis against competing hypotheses presented by other students (Singer et al. 2001). After refining a hypothesis about the evolutionary relationships or the evolution of characters of interest, students present their hypothesis in the form of a research paper. This type of exercise parallels one form of scientific inquiry, in which observation, data collection, and hypothesis testing are followed by reporting one's results (Giese 2005; Julius and Schoenfuss 2006). This exercise should be followed by critical reflection to reinforce NOS concepts (i.e., tentative and subjective nature of scientific knowledge, importance of human creativity, observation versus inference) that were covered (Abd-El-Khalick and Lederman 2000).

To further emphasize how characters can be mapped onto trees, units of a course or an entire course can be taught upon a tree (Baum and Offner 2008; Smith and Cheruvelil 2009). This approach is valuable because using an evolutionary framework to unify the material in an introductory biology course should improve students' understanding of evolution (Nehm et al. 2009). As an example, I have taught energy metabolism by comparing the cellular metabolic properties of different clades. The evolution of different metabolic characters can be mapped on a tree, and students can infer how extant species obtain energy based on the phylogeny. This approach can also be used to study the evolution of characters in specific clades, and it is easily applied to lessons on animal or plant physiology (Baum and Offner 2008). Laboratory exercises on these topics can be designed within an inquiry-based framework to encourage critical thinking and scientific reasoning (Smith and Cheruvelil 2009). The instructor can explain how new evidence leads one to different hypotheses about evolutionary relationships. This demonstrates that scientific knowledge is continuously changing based on new discoveries (Baum and Offner 2008), an important component of NOS (Abd-El-Khalick et al. 1998; Lederman 1998).

\section{Exceptions to Tree-Thinking}

All living organisms on Earth have been placed in a single tree of life (Woese et al. 1990), and lessons have been designed to teach biology within the framework of this universal tree of life (Offner 2001; Staub et al. 2009). This tree of life consists of three domains: eukaryotes (including animals, plants, fungi, and a vast array of single-celled organisms united by multiple shared characters, such as a intracellular membrane-bound organelles), archaea (singlecelled organisms, many of which are capable of living in extreme environments), and bacteria (Fig. 4a). Archaea and bacteria are collectively referred to as prokaryotes because
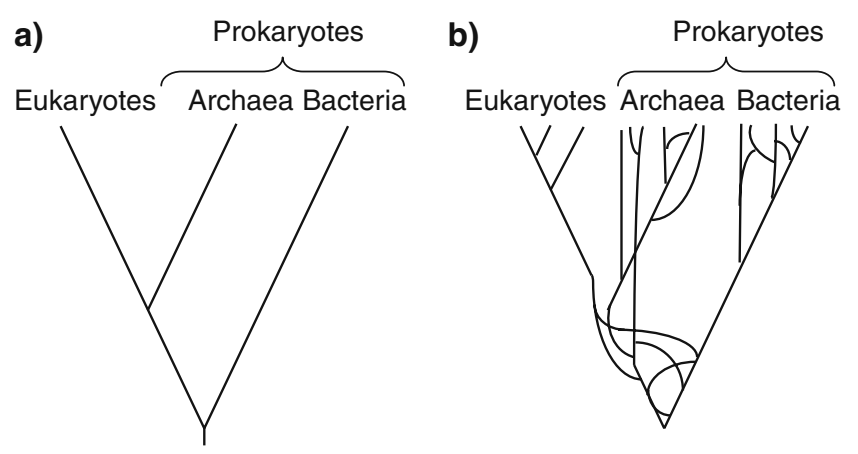

Fig. 4 Two different examples of the universal tree of life are shown. a In the simplified version, linear descent from a common ancestor is assumed. b In the more complex version, horizontal gene transfer is common amongst prokaryotic organisms, violating the assumption of linear descent. Additionally, the complex version contains a representation of the endosymbiosis event that gave rise to the eukaryotes 
they lack many of the sub-cellular structures found in eukaryotes, but this is not a monophyletic clade (Fig. 4a).

A tree-like representation of all life assumes vertical decent from a common ancestor, but this assumption has been extensively criticized in the scientific literature (e.g., Doolittle 1999; Doolittle and Bapteste 2007; Koonin and Wolf 2008). The origin of eukaryotes, for instance, probably involved at least one fusion of archaeal and bacterial species (Schwartz and Dayhoff 1978; Rivera and Lake 2004), suggesting that the root of the tree of life violates the assumption of bifurcation (Fig. 4b). Furthermore, horizontal transfer of genes is common between prokaryotic species (Lawrence and Ochman 1998; Philippe and Douady 2003), violating the assumption of vertical descent from a common ancestor (Fig. 4b). Vertical descent is the norm amongst many eukaryotic clades, however, and a tree-like representation may be appropriate near the tips of prokaryotic trees (Creevey et al. 2004). Additionally, while the species-level relationships may not be represented by simple bifurcations, phylogenies of individual genes should yield bifurcating trees (Maddison 1997; Wolf et al. 2002). Despite the non-tree-like nature of deep evolutionary relationships, tree-thinking should still be emphasized in biology curricula. Phylogenetic trees do accurately represent evolutionary relationships within many of the clades in which the evolution of characters are taught (Gilbert 2003; Baum and Offner 2008; Smith and Cheruvelil 2009), and students can only appreciate the fascinating complexities of deep evolutionary relationships and horizontal gene transfer between prokaryotes if they understand the simple expectations of vertical transmission.

A common approach for teaching phylogenetics is to have students build trees to show the relationships between manufactured products, such as hardware or furniture (Nickels and Nelson 2005). In a phylogeny of species, the tree represents lines of descent from common ancestors. Classifications of manufactured goods, however, do not represent vertical descent from a common ancestor (Nickels and Nelson 2005). Instead, these are created objects that draw on design elements from other objects. While using manufactured objects to represent traditional vertical descent is inappropriate, manufactured goods provide a nice example of horizontal transfer (Tëmkin and Eldredge 2007). As students become more comfortable with tree-thinking, they can be presented with the many exceptions to vertical transmission, and manufactured goods could be useful in introducing the concept of horizontal transmission. Examples of such manufactured products include hardware (Nickels and Nelson 2005) and musical instruments (Tëmkin and Eldredge 2007). A possible exercise involves having students construct the relationships of a set of similar products (e.g., nails, bolts, and screws). Students are confronted with the realization that certain design elements are "inherited" from a MRCA, some are novel to a particular product or group of products (synapomorphies), and others are borrowed from existing products (horizontally transferred). This exercise demonstrates that manufactured goods can be used to teach tree-thinking while remaining true to accepted evolutionary processes.

\section{Conclusions}

Developing students' tree-thinking skill has been a challenge to biology instructors. Many of the approaches and exercises presented here have been shown to improve students' conceptual understanding of evolutionary trees. Tree-thinking should be introduced to students using an inquiry-based approach, allowing students to confront their preconceptions through experimentation. Throughout these lessons, relevant NOS concepts should be explicitly discussed to improve students' understanding of the scientific process. Once students develop a basic grasp of tree-thinking, the required material in a course should be presented within a phylogenetic context to reinforce their tree-thinking skills. Finally, exceptions to the traditional bifurcating trees can be presented to the students once they understand the expectations of vertical transmission.

Acknowledgements Two anonymous reviewers provided comments that greatly improved this work. RPM is supported by NIH fellowship F32GM087611.

\section{References}

Abd-El-Khalick F, Bell RL, Lederman NG. The nature of science and instructional practice: making the unnatural natural. Sci Educ. 1998;82:417-36.

Abd-El-Khalick F, Lederman NG. Improving science teachers' conceptions of nature of science: a critical review of the literature. Int J Sci Educ. 2000;22:665-701.

Baum DA, Smith SD, Donovan SS. Evolution: the tree-thinking challenge. Science. 2005;310:979-80.

Baum DA, Offner S. Phylogenies and tree-thinking. Am Biol Teach. 2008;70:222-9.

Catley K, Lehrer R, Reiser B. Tracing a prospective learning progression for developing understanding of evolution. http:// www7.nationalacademies.org/bota/Evolution.pdf (2005).

Catley KM. Darwin's missing link-a novel paradigm for evolution education. Sci Educ. 2006;90:767-83.

Catley KM, Novick LR. Seeing the wood for the trees: an analysis of evolutionary diagrams in biology textbooks. Bioscience. 2008;58:976-87.

Catley KM, Novick LR, Shade CK. Interpreting evolutionary diagrams: when topology and process conflict. J Res Sci Teach. 2010;10.1002/tea.20384.

Creevey CJ, Fitzpatrick DA, Philip GK, Kinsella RJ, O'Connell MJ, Pentony MM, et al. Does a tree-like phylogeny only exist at the tips in the prokaryotes? Proc R Soc Lond B Biol Sci. 2004;271: 2551-8. 
Crisp MD, Cook LG. Do early branching lineages signify ancestral traits? Trends Ecol Evol. 2005;20:122-8.

Dobzhansky T. Nothing in biology makes sense except in the light of evolution. Am Biol Teach. 1973;35:125-9.

Doolittle WF. Phylogenetic classification and the universal tree. Science. 1999;284:2124-8.

Doolittle WF, Bapteste E. Pattern pluralism and the Tree of Life hypothesis. Proc Natl Acad Sci USA. 2007;104:2043-9.

Gee H. Progressive evolution: aspirational thinking. Nature. 2002;420:611.

Giese AR. Using inquiry and phylogeny to teach comparative morphology. Am Biol Teach. 2005;67:412-7.

Gilbert SF. Opening Darwin's black box: teaching evolution through developmental genetics. Nat Rev Genet. 2003;4:735-41.

Goldsmith DW. The great clade race: presenting cladistic thinking to biology majors \& general science students. Am Biol Teach. 2003;65:679-82.

Gregory TR. Understanding evolutionary trees. Evo Edu Outreach. 2008;1:121-37.

Gregory TR. Understanding natural selection: essential concepts and common misconceptions. Evo Edu Outreach. 2009;2:156-75.

Gregory TR, Ellis CAJ. Conceptions of evolution among science graduate students. Bioscience. 2009;59:792-9.

Halverson KL. Using pipe cleaners to bring the tree of life to life. Am Biol Teach. 2010;72:223-4

Haukoos GD, Penick JE. The influence of classroom climate on science process and content achievement of community college students. J Res Sci Teach. 1983;20:629-37.

Jensen MS, Finley FN. Changes in students' understanding of evolution resulting from different curricular and instructional strategies. J Res Sci Teach. 1996;33:879-900.

Julius ML, Schoenfuss HL. Phylogenetic reconstruction as a broadly applicable teaching tool in the biology classroom: the value of data in estimating likely answers. J Coll Sci Teach. 2006;35: $40-5$.

Koonin EV, Wolf YI. Genomics of bacteria and archaea: the emerging dynamic view of the prokaryotic world. Nucleic Acids Res. 2008;36:6688-719.

Krell FT, Cranston PS. Which side of the tree is more basal? Syst Entomol. 2004;29:279-81.

Lawrence JG, Ochman H. Molecular archaeology of the Escherichia coli genome. Proc Natl Acad Sci USA. 1998;95:9413-7.

Lawson AE. A better way to teach biology. Am Biol Teach. 1988;50:266-78.

Lederman NG. Students' and teachers' conceptions of the nature of science: a review of the research. J Res Sci Teach. 1992;29: 331-59.

Lederman NG. The state of science education: subject matter without context. Elec J Sci Educ. 1998;3 (guest editorial).

Lovejoy AO. The great chain of being: a study of the history of an idea. Cambridge: Harvard University Press; 1936.

Maddison WP. Gene trees in species trees. Syst Biol. 1997;46:523-36.

Mazur E. Education: farewell, lecture? Science. 2009;323:50-1.

Meir E, Perry J, Herron JC, Kingsolver J. College students' misconceptions about evolutionary trees. Am Biol Teach. 2007;69:e71-6.

Musheno BV, Lawson AE. Effects of learning cycle and traditional text on comprehension of science concepts by students at differing reasoning levels. J Res Sci Teach. 1999;36:23-37.

Nee S. The great chain of being. Nature. 2005;435:429.

Nehm R, Poole T, Lyford M, Hoskins S, Carruth L, Ewers B, et al. Does the segregation of evolution in biology textbooks and introductory courses reinforce students' faulty mental models of biology and evolution? Evo Edu Outreach. 2009;2:527-32.

Nei M, Kumar S. Molecular evolution and phylogenetics. Oxford: Oxford University Press; 2000.

Nickels MK, Nelson CE. Beware of nuts \& bolts: putting evolution into the teaching of biological classification. Am Biol Teach. 2005;67:283-9.

Novick L, Catley K, Funk D. Characters are key: the effect of synapomorphies on cladogram comprehension. Evo Edu Outreach. 2010;10.1007/s12052-12010-10243-z.

Novick LR, Catley KM. Understanding phylogenies in biology: the influence of a Gestalt perceptual principle. J Exp Psychol Appl. 2007; 13:197-223.

O'Hara RJ. Population thinking and tree thinking in systematics. Zool Scr. 1997;26:323-9.

Offner S. A universal phylogenetic tree. Am Biol Teach 2001:63:164-70.

Omland KE, Cook LG, Crisp MD. Tree thinking for all biology: the problem with reading phylogenies as ladders of progress. BioEssays. 2008;30:854-67.

Page RDM, Holmes EC. Molecular evolution: a phylogenetic approach. Oxford: Blackwell Science; 1998.

Perry J, Meir E, Herron JC, Maruca S, Stal D. Evaluating two approaches to helping college students understand evolutionary trees through diagramming tasks. CBE Life Sci Educ. 2008;7:193-201.

Philippe H, Douady CJ. Horizontal gene transfer and phylogenetics. Curr Opin Microbiol. 2003;6:498-505.

Rivera MC, Lake JA. The ring of life provides evidence for a genome fusion origin of eukaryotes. Nature. 2004;431:152-5.

Rudolph JL, Stewart J. Evolution and the nature of science: on the historical discord and its implications for education. J Res Sci Teach. 1998;35:1069-89.

Sandvik H. Tree thinking cannot be taken for granted: challenges for teaching phylogenetics. Theory Biosci. 2008;127:45-51.

Sandvik H. Anthropocentricisms in cladograms. Biol Philos. 2009;24:425-40.

Schwartz RM, Dayhoff MO. Origins of prokaryotes, eukaryotes, mitochondria, and chloroplasts. Science. 1978;199:395-403.

Singer F, Hagen JB, Sheehy RR. The comparative method, hypothesis testing \& phylogenetic analysis: an introductory laboratory. Am Biol Teach. 2001;63:518-23.

Smith JJ, Cheruvelil KS. Using inquiry and tree-thinking to "march through the animal phyla": teaching introductory comparative biology in an evolutionary context. Evo Edu Outreach. 2009;2:429-44.

Smith MK, Wood WB, Adams WK, Wieman C, Knight JK, Guild N, et al. Why peer discussion improves student performance on inclass concept questions. Science. 2009;323:122-4.

Staub NL, Pauw PG, Pauw D. Seeing the forest through the trees: helping students appreciate life's diversity by building the tree of life. Am Biol Teach. 2009;68:149-51.

Tëmkin I, Eldredge N. Phylogenetics and material cultural evolution. Curr Anthropol. 2007;48:146-54.

Treagust D, Duit R. Conceptual change: a discussion of theoretical, methodological and practical challenges for science education. Cult Stud Sci Educ. 2008;3:297-328.

Woese CR, Kandler O, Wheelis ML. Towards a natural system of organisms: proposal for the domains Archaea, Bacteria, and Eucarya. Proc Natl Acad Sci USA. 1990;87:4576-9.

Wolf YI, Rogozin IB, Grishin NV, Koonin EV. Genome trees and the tree of life. Trends Genet. 2002;18:472-9. 